\title{
Molecular epidemiology and seroprevalence in asymptomatic Plasmodium falciparum infections of Malagasy pregnant women in the highlands
}

Oumou Maïga-Ascofaré ${ }^{*}$, Raphael Rakotozandrindrainy², Mirko Girmann', Andreas Hahn', Njary Randriamampionona², Sven Poppert ${ }^{3}$, Jürgen May ${ }^{1}$ and Norbert G Schwarz

\begin{abstract}
Background: Malaria epidemiology in Madagascar is classified into four different areas, ranging from unstable seasonal transmission in the highlands to hyperendemic perennial transmission areas in the costal level. Most malaria studies in Madagascar are focused on symptomatic children. However, because of the low transmission in some areas with correspondingly low level of semi-immunity, adults are also at risk, in particular pregnant women. The objective of this study was to gain information on the genetic epidemiology of malarial infections in pregnant women in order to provide information for malaria control and elimination programmes in Madagascar.

Methods: Between May and August 2010, we carried out cross-sectional surveys targeting healthy pregnant women in six locations, three in the coastal area and three in the highlands at 850-1300 m. 1244 blood samples were screened for anti-Plasmodium falciparum antibodies by immunofluorescence test and for malarial infection by realtime-PCR. The prevalence of chloroquine and sulphadoxine-pyrimethamine resistance markers was also determined in all Plasmodium falciparum samples by PCR-RFLP as well as the multiplicity of infection through genotyping six neutral microsatellites.
\end{abstract}

Results: In the highlands, $67.4 \%$ of the women presented antibodies against Plasmodium falciparum and $9.2 \%$ were carrying parasites, at the coast $95.6 \%$ and $14.8 \%$, respectively. In the mean, 1.2 clones were detected in infected pregnant woman in the highlands and 1.5 at the coast. A higher level of monoclonal infections was found in the highlands (85.4\%) compared to the coast (61.8\%). Resistance markers for sulphadoxine-pyrimethamine were present only in two sites.

Conclusion: Immunity is triggered in Malagasy highland populations when they are infected with malaria parasites, but these populations could also serve as a reservoir for epidemics.

Keywords: Madagascar, Pregnancy, Plasmodium falciparum, Seroprevalence, Drug resistance, Multiplicity of infection

\section{Background}

Asymptomatic carriage of malaria parasites is common in adults in endemic regions and provides a reservoir for gametocytes, the forms of the parasite infectious to mosquitoes and thus responsible for cross-species transmission [1]. These asymptomatic carriers may be of particular importance in the highland regions of Madagascar, where malaria can be absent over years, but may reappear epidemically, like between 1986 and 1988 where malaria

\footnotetext{
* Correspondence: maiga@bni-hamburg.de

'Bernhard-Nocht Institute for Tropical Medicine, Hamburg, Germany

Full list of author information is available at the end of the article
}

outbreaks had devastating effects on a virtually nonimmune population [2,3]. Malaria parasites found on the island of Madagascar are Plasmodium falciparum, Plasmodium vivax and to a minor degree Plasmodium malariae and Plasmodium ovale [4]. The main malaria vector in the Madagascan highlands is Anopheles funestus that once had disappeared after extensive insecticide spraying in the 1950s, but reappeared in the 1980s [5] leading to epidemics that caused several ten thousand of deaths in the 1980s and 1990s [6].

The country has been classified in four distinct malaria epidemiologic zones based on the geography and the 
length and intensity of malaria transmission. Malaria transmission is stable and perennial at the East Coast, stable and long seasonal at the West Coast and unstable and seasonal in the Central Highlands and the Semi-desert zones of the South [4]. On the East and West Coast, exposure and thus immunity among adults is reported to be high and most morbidity and mortality is among children under five and pregnant women. In the upper Central Highlands and the South immunity is limited making the population vulnerable to epidemics especially during the rainy season (from late October/early November until May).

Since 2008, The National Malaria Control Programme (NMCP) of Madagascar received international support through funds from the Global Funds, the World Health Organization and the US President's Malaria Initiative as help in their fight to eradicate malaria from the island [7]. Nevertheless, only little is known on the recent epidemiology of $P$. falciparum infections in the country $[8,9]$. Most studies were performed in symptomatic children while parasite reservoirs in asymptomatic carriers could hamper the progress of malaria control and eradication efforts. Therefore, active detection of infected carrier could be useful for a malaria elimination programme [10].

This study explored the prevalence of asymptomatic malaria carriers in two of the four epidemiological areas in Madagascar. Blood samples collected in 2010 from 1,244 asymptomatic pregnant women from three coastal and three highland cities were investigated for: (i) the presence of malaria parasites, (ii) the seroprevalence of anti- $P$. falciparum antibodies, (iii) the multiplicity of infection and (iv) the presence of drug resistance markers for sulphadoxine-pyrimethamine (SP) and chloroquine (CQ).

\section{Methods}

\section{Study sites}

A cross-sectional survey was carried out between May and July 2010 in antenatal clinics in six different locations (Figure 1). The Central highlands of Madagascar are mainly on an altitude between 800 to $1,400 \mathrm{~m}$ above sea level. The three highland cities included in this study were Tsiroanomandidy $(860 \mathrm{~m})$, Moramanga $(920 \mathrm{~m})$, and Ambositra $(1,280 \mathrm{~m})$. From the central highlands the land descends over a steep fall into a ribbon of rainforest that reaches to the east coast. Mananjary and Manakara are on sea level at the east coast, and Ifanadiana is a $460 \mathrm{~m}$ high settlement located on the steep slope from the east coast to the highlands. The three first locations are later in this report defined as the 'highlands' and the three last as the 'coast'. Mananjary and Manakara were affected by an outbreak of chikungunya 3-5 months before this study took place [11].

The study was approved by the "Comité d'éthique de la Vice Primature Chargée de la Santé Publique" from Madagascar. The study was explained to the pregnant

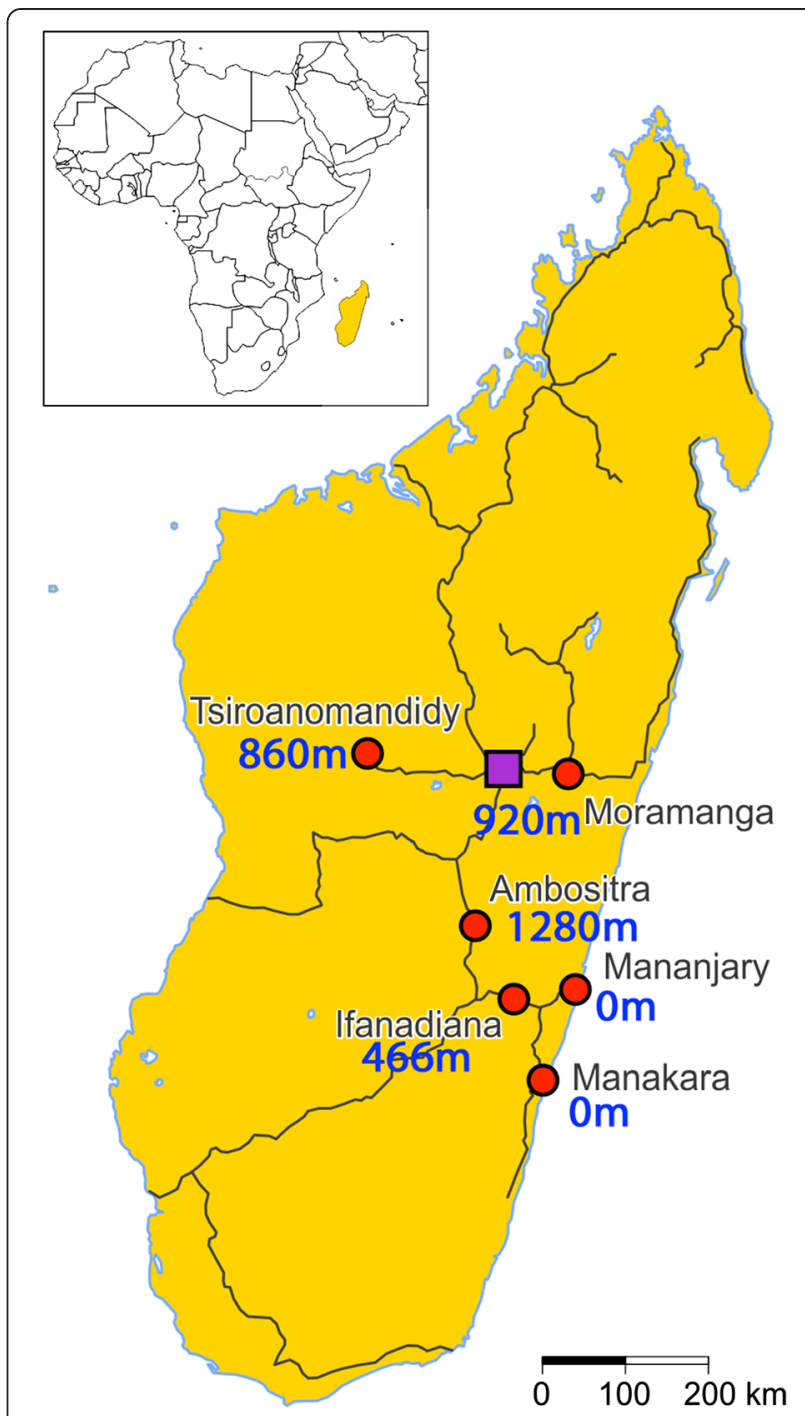

Figure 1 Map of Madagascar showing the six study locations with their altitude. The red circles indicate the six study locations and the purple square the capital Antananarivo. The black lines represent the main roads for long distance travel.

women and their written informed consent was sought. In case of illiteracy the study was explained and approval of participation expressed through a fingerprint and signature of a witness.

\section{Sample collection}

A venous (EDTA) blood sample was taken and the plasma was extracted by centrifugation. The supernatant was stored at $-20^{\circ} \mathrm{C}$ for serological analysis. Five hundred microlitre of the pellet was taken and diluted with the same amount of $8 \mathrm{M}$ Urea solution $(\mathrm{v} / \mathrm{v})$ that is appropriate for conserving the sample at $+4^{\circ} \mathrm{C}$ for later DNA extraction. 


\section{Detection of antibodies by serology}

Serology for the detection of antibodies (IgG + IgA + IgM) directed against Plasmodium falciparum was performed by an in-house indirect immunofluorescence antibody test (IFAT). Plasma samples were diluted to 1:40 with PBS plus milk powder $3 \%$. Twenty $\mu \mathrm{L}$ of the diluted plasma were applied to an antigen field, and were incubated for $30 \mathrm{~min}$ at $37^{\circ} \mathrm{C}$. One positive control and one negative control were included in each series. The slides were washed three times for $5 \mathrm{~min}$ in PBS and dried before adding fluorescein-labelled total human anti-Ig conjugate (Sifin, Berlin, Germany) diluted at 1/200 in PBS containing Evans blue $(0.1 \mathrm{~g} / \mathrm{L})$. After incubation for $30 \mathrm{~min}$ at $37^{\circ} \mathrm{C}$ in a humid chamber, the slides were again washed three times for $5 \mathrm{~min}$ in PBS. The slides were read under a fluorescence microscope (Zeiss) with UV-illumination at a magnification of 250. Samples fluorescing at 1/40 dilution were considered positive. An exact titer of the positive samples was not determined.

The in-house immunofluorescence test itself was manufactured using the laboratory strain 3D7 as antigen. The Plasmodium strain was cultured in red blood cells obtained from German Red Cross Blood Bank as described elsewhere [12]. Erythrocytes containing mature parasite forms were purified using a commercially available magnetic cell fractionation system (MACS system; Miltenyi Biotec). The purified erythrocytes were applied to glass slides with 12 fields (Thermo Scientific, Dreieich, Germany), air dried and stored at $-70^{\circ} \mathrm{C}$ for long-term storage and subsequently at $-20^{\circ} \mathrm{C}$ few days before usage. After thawing, the antigen slides were fixed in acetone/ methanol solution $(\mathrm{v} / \mathrm{v})$ for $5 \mathrm{~min}$ at $4^{\circ} \mathrm{C}$.

\section{Molecular genotyping DNA extraction}

DNA was extracted from $400 \mu \mathrm{L}$ of peripheral venous blood-EDTA/8 M urea (v/v) using the QIAamp ${ }^{\circ}$ DNA Blood mini Kit according to the manufacturer's protocol (Qiagen).

\section{Molecular detection of malarial species}

Four Plasmodium species with human as host were assessed by real-time PCR methodology based on Fluorescence Resonance Energy Transfer technology. P. falciparum was detected with primers and probes targeting the cox 1 gene and $P$. ovale, $P$. malariae and $P$. vivax with primers and probes targeting the 185 rDNA (Additional file 1).

On a LightCycler 480 (Roche), the PCR was carried out in a total volume of $20 \mu \mathrm{L}$ containing $5 \mu \mathrm{L}$ of extracted genomic DNA or plasmids including the gene targeted for each species as positive control. The mixture to detect $P$. falciparum contained $0.2 \mathrm{mM}$ dNTPs, $3.5 \mathrm{mM} \mathrm{MgCl}, 0.4 \mu \mathrm{M}$ of forward primer, $0.5 \mu \mathrm{M}$ of reverse primer, $0.15 \mu \mathrm{M}$ each of the donor and acceptor probes, $0.25 \mathrm{~g} / \mathrm{l}$ bovine serum albumin (BSA) and $0.5 \mathrm{U}$ Taq polymerase (Platinium, Invitrogen). The multiplex PCR to detect $P$. malariae, $P$. ovale and $P$. vivax used three forward primers; each primer is specific of one species and one reverse primer for the three species. The mixture differed from the first one by primer concentration: $0.7 \mu \mathrm{M}$ of forward primer for P. malariae, $0.5 \mu \mathrm{M}$ of each forward primer for $P$. ovale and $P$. vivax, $0.4 \mu \mathrm{M}$ of reverse primer.

For both PCRs, the following PCR programme was used: 2 min at $95^{\circ} \mathrm{C} ; 10$ touchdown repeated cycles of $5 \mathrm{sec}$ at $95^{\circ} \mathrm{C}, 10 \mathrm{sec}$ at $63^{\circ} \mathrm{C}$ to $58^{\circ} \mathrm{C}, 7 \mathrm{sec}$ at $72^{\circ} \mathrm{C}$; and 45 repeated cycle of $5 \mathrm{sec}$ at $95^{\circ} \mathrm{C}, 10 \mathrm{sec}$ at $58^{\circ} \mathrm{C}, 7 \mathrm{sec}$ at $72^{\circ} \mathrm{C}$. Melting analysis was performed by denaturing for $30 \mathrm{sec}$ at $95^{\circ} \mathrm{C}$ and cooling for $2 \mathrm{~min}$ to $45^{\circ} \mathrm{C}$ followed by heating at the rate of $0.1^{\circ} \mathrm{C} / \mathrm{s}$ from $45^{\circ} \mathrm{C}$ to $75^{\circ} \mathrm{C}$.

\section{Assessing multiplicity of infection of Plasmodium falciparum}

To determine the minimal number of distinguishable clones per isolate, we genotyped 6 different neutral highly polymorphic, microsatellites ARA2 (chr 11, Genbank accession no. X17484), PfPK2 (chr 12, X63648), TA60 (chr 13, AF010556), TA81 (chr 5, AF010510), TA87 (chr 6, AF010571), Poly alpha (chr 4, L18785). The multiplicity of infection (MOI) was quantified as the "highest number of fragments" for one of the microsatellites genotyped.

The six microsatellite loci were amplified by semi-nested PCR according to a previous publication [13] with few modifications. Three outer PCR duplexes were performed followed by six nested PCRs. Each outer PCR mixture $(50 \mu \mathrm{L})$ contained $6 \mu \mathrm{L}$ of DNA, $3 \mathrm{mM} \mathrm{MgCl}_{2}, 200 \mu \mathrm{M}$ dNTPs, $50 \mathrm{nM}$ for each primer (4 in total for Polyalpha and TA60, TA81 and ARA2 or PfPK2 and TA87; Additional file 1) and 1.25 U Taq polymerase (GoTaq, Promega). The sequences of all primers used are shown in Additional file 1. Cycling conditions were as follows: 2 min at $94^{\circ} \mathrm{C}$; 25 repeated cycles of $30 \mathrm{sec}$ at $94^{\circ} \mathrm{C}$, $30 \mathrm{sec}$ at $42^{\circ} \mathrm{C}, 30 \mathrm{sec}$ at $40^{\circ} \mathrm{C}, 40 \mathrm{sec}$ at $65^{\circ} \mathrm{C} ; 2 \mathrm{~min}$ at $65^{\circ} \mathrm{C}$. Each nested PCR mixture contained $1 \mu \mathrm{L}$ of the outer PCR, $2.5 \mathrm{mM} \mathrm{MgCl}_{2}, 200 \mu \mathrm{M}$ dNTPs, $150 \mathrm{nM}$ for each primer and $1 \mathrm{U}$ Taq polymerase (GoTaq, Promega). Cycling conditions were as follows: $2 \mathrm{~min}$ at $94^{\circ} \mathrm{C} ; 25$ repeated cycles of $20 \mathrm{sec}$ at $94^{\circ} \mathrm{C}, 20 \mathrm{sec}$ at $45^{\circ} \mathrm{C}$ and $30 \mathrm{sec}$ at $65^{\circ} \mathrm{C} ; 2 \mathrm{~min}$ at $65^{\circ} \mathrm{C}$. Amplified fragments were analysed on an ABI 3130 Genetic Analyzer and by GeneMapper ${ }^{\ominus}$ software version 4.0 (Applied Biosystems) to measure the variable length in the samples.

\section{Detection of Plasmodium falciparum drug resistance markers} by nested PCR-RFLP

For this study, the polymorphism of $p f d h f r$ at codons N51I, C59R, S108N and I164L, pfdhps at codons A437G and K540E, pfcrt at codon K76T and pfmdr1 at codon 
N86Y were genotyped as described previously [14]. Because we suspected low parasitaemia, the outer PCR mixtures were carried out in a total volume of $50 \mu \mathrm{L}$ containing $6 \mu \mathrm{L}$ of template DNA. DNA from two P. falciparum strains (3D7, and W2mef) was used as controls for the PCR and the digestion.

\section{Sample size calculations}

For this study, the aim was to detect at least one pregnant woman with malaria parasites if the real prevalence was $2.5 \%$ with a $90 \%$ probability. Using binomial distribution as a proxy for a hypergeometrical distribution, the required sample size of 152 was calculated. Therefore aimed to include at least 160 women per study site. With 200 pregnant women per study site, the $90 \%$ probability to detect at least one parasitized women holds even if the real prevalence is only $2 \%$.

\section{Statistical analysis}

For the statistical analysis of the study univariate tests were performed. All categorical variables were analysed conducting Fisher's exact tests. As a normal distribution of the MOI could not be assumed Mann Whitney's U test and Kruskall Wallis test as the non-prarametric equivalent to an ANOVA were conducted for this variable. The two-sided significance level for all tests was set to 0.05 and not adjusted for multiple testing as the study was planned as a descriptive study.

\section{Results}

Overall, 1,244 pregnant women were included into the study. In all study locations, the age distribution was right skewed with a median age of 25 years (range 12-50). Subsequently, different variables were analysed according to two age groups defined as up to 19 years and, 20 years and over. Nine out of 601 women questioned from the highlands claimed to travel within the last half of a year and only one of these travels was to a coastal location.

The proportion of primiparae was similar in the highlands and at the coast (28.4\% and $30.3 \%$, respectively). The only noteworthy mosquito protective measures that were used frequently were bed nets $(70.3 \%)$. The use of bed nets was more common in the coastal cities of Mananjary (90.5\%), Manakara (91.2\%) and Ifanadiana (94.4\%) compared to the highland cities of Tsironoamandidy (56.7\%), Moramanga (67.0\%) and Ambositra (21.5\%). Intermittent presumptive treatment in pregnancy (IPTp) was reported by $41.3 \%$ overall. The proportion of women who had received IPTp was higher at the coast than in the highlands ( $\mathrm{p}>0.001)$ (Table 1).

\section{Prevalence of anti-Plasmodium falciparum antibodies}

The prevalence of antibodies directed to P. falciparum was determined using an IFAT for 1216 samples where serum or plasma was available. In the coastal areas, the seroprevalence was very high with $95.6 \%$ of the samples (Figure 2). The prevalence according to age categories up to 19 years and, from 20 years and over were similar with $93.7 \%$ and $95.9 \%$, respectively. In the highlands, the seroprevalence was slightly lower with $87.1 \%$ in Tsiroanomandidy and $84.8 \%$ in Moramanga. In those two locations, the seroprevalence was also equivalent according to age groups. In Ambositra, located higher than 1,280 m above sea level, antibodies against $P$. falciparum were detected only in $30.4 \%$ of the pregnant women. The seroprevalence was lower in the pregnant group up to 19 years with $25.9 \%$ than in the group of 20 years and over with $30.4 \%$.

\section{Prevalence of infection}

Of all 1,242 blood samples, 157 (12.6\%) were PCRpositive for $P$. falciparum, nine for $P$. malariae, one for $P$. ovale and one for $P$. vivax; six mixed infections were found (Table 2). With $14.8 \%$ the mean of infected pregnant women was higher at the coast than at highland locations $(9.2 \%, \mathrm{p}<0.001)$. In Ifanadiana, which is situated $466 \mathrm{~m}$ above sea level on the ascend from the coastal study sites to the highlands, prevalence of $9.6 \%$ was found, slightly lower than two of the three sites in the highlands: Tsironomandidy (10.3\%) and Moramanga (13.6\%).

At the coast, the prevalence of infection was lower in pregnant women using prophylaxis than in women without prophylaxis. With IPTp, the prevalence was $14.0 \%$ vs. $18.9 \%$ and with bed net use; it was $14.2 \%$ vs. $21.6 \%$, respectively (Table 3). For the analysis of the MOI and for

Table 1 Prevalence of primigravidae women, bed net use and uptake of IPTp at six locations in Madagascar

\begin{tabular}{|c|c|c|c|c|c|c|c|c|c|c|c|c|c|c|}
\hline & \multicolumn{6}{|c|}{ Coast } & \multicolumn{6}{|c|}{ Highlands } & \multirow{2}{*}{\multicolumn{2}{|c|}{ Total }} \\
\hline & \multicolumn{2}{|c|}{ Mananjary } & \multicolumn{2}{|c|}{ Manakara } & \multicolumn{2}{|c|}{ Ifanadiana } & \multicolumn{2}{|c|}{ TDD } & \multicolumn{2}{|c|}{ Moramanga } & \multicolumn{2}{|c|}{ Ambositra } & & \\
\hline & $\bar{N}$ & $+(\%)$ & $\bar{N}$ & $+(\%)$ & $\bar{N}$ & $+(\%)$ & $\mathrm{N}$ & $+(\%)$ & $\bar{N}$ & $+(\%)$ & $\bar{N}$ & $+(\%)$ & $\mathbf{N}$ & $+(\%)$ \\
\hline primigravidae & 188 & $64(34.4)$ & 245 & $58(23.7)$ & 178 & $48(27.0)$ & 202 & $63(31.2)$ & 196 & 66 (33.7) & 190 & $49(25.8)$ & 1199 & $348(29.0)$ \\
\hline Bed net use & 190 & $172(90.5)$ & 250 & $228(91.2)$ & 197 & $186(94.4)$ & 203 & $115(56.7)$ & 194 & $130(67.0)$ & 200 & $43(21.5)$ & 1234 & 874 (70.8) \\
\hline IPTp/SP & 190 & $88(46.3)$ & 243 & $96(39.5)$ & 196 & $126(64.3)$ & 198 & $95(48.0)$ & 191 & $89(46.6)$ & 190 & $5(2.6)$ & 1208 & $499(41.3$ \\
\hline
\end{tabular}

TDD, Tsiroanomandidy.

IPTp/SP, Intermittent Presumptive Treatment in pregnancy with sulphadoxine-pyrimethamine.

$\mathrm{N}$, Number of participants who answered the questionnaire.

+ , Number of primigravidae participants or participants who claimed to use bed net or IPTp/SP as prophylaxes. 


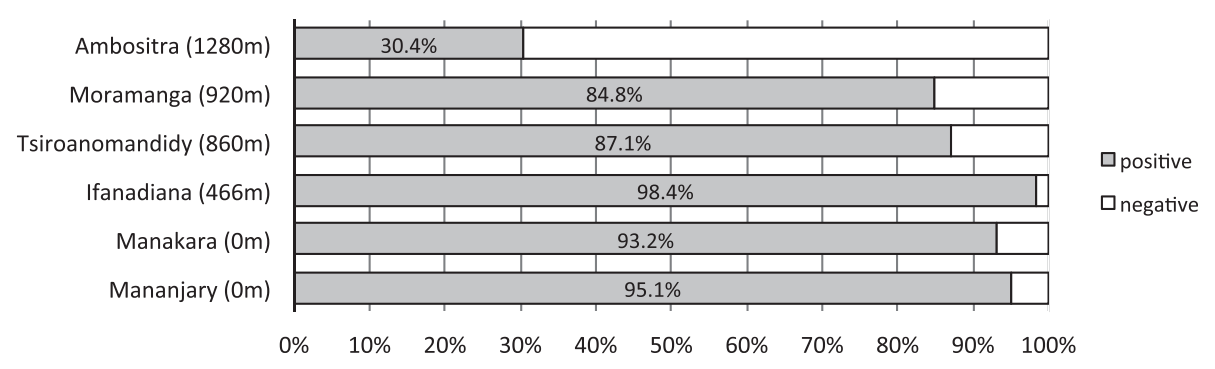

Figure 2 Seroprevalence of anti-Plasmodium falciparum antibodies in pregnant women in six locations of Madagascar. The altitude of each site is indicated in brackets. The grey bars indicate the percentage of seropositive samples and the white bar the seronegative samples.

the detection of drug resistant markers, only the 152 samples that were mono-infected by $P$. falciparum were included.

\section{Multiplicity of infection}

The six neutral microsatellites genotyped in this study were highly polymorphic in the six locations with a number of alleles from nine for ARA2 and TA60 to 14 for PfPK2. The MOI could be determined for 116/152 samples by at least one microsatellite. The highest maximal number of different parasite clones detected in one pregnant woman was four in a costal location (Mananjary) with PfPk2. The average number of different clones found in infected pregnant woman was 1.4 and it was higher at the coast level $(1.5,95 \%$ CI: 1.3-1.7) than in the highlands (1.2, 95\% CI: 1.0-1.3; $\mathrm{p}=0.005)$ (Figure 3). The prevalence of $P$. falciparum monoclonal infection was $61.8 \%$ at the coast against $85.4 \%$ in the highlands $(\mathrm{p}=$ 0.005) (Table 4). According to the group of age, the MOI was higher in the group of pregnant women up to 19 years with 1.55 than in the one from 20 and over with 1.3 (Table 5). The MOI was slightly higher in the group of pregnant women who didn't use IPTp than in the one who used the chemoprophylaxis in the highlands (1.21 vs.
$1.06)$ and at the coast (1.52 vs. 1.44) (Table 5). Furthermore, the use of bed net was significantly associated with the reduction of MOI ( 2 vs. $1.43, \mathrm{p}=0.028)$ in the coast level (Table 5).

\section{Prevalence of drug resistance markers}

Overall 152 isolates were screened for eight drug resistance markers against SP (dhfr N51I, C59R, S108N, I164L and dhps A437G, K540E) and CQ (pfcrt K76T and pfmdr1 N86Y); 118 (77.6\%) samples were successful genotyped for at least one of the eight markers. Figure 4 gives an overview of the proportional distributions of wild type, mutant and mixed type in the different study locations. The allele dhfr triple mutant 51I, 59R, 108N were polymorphic only in Manakara and Tsiroanomandidy with a prevalence of $20 \%(6 / 30)$ and $25 \%(2 / 8)$, respectively. The allele $d h f r 164 \mathrm{~L}$ was genotyped in three samples from the coast. The allelic frequency of dhps 437G was variable among the different locations $(\mathrm{p}=$ 0.02 ). With $71.6 \%$, the prevalence of the mutant was higher at the coast compared to the highlands with 27.3\% ( $\mathrm{p}<0.001)$. Overall positive samples for $d h f r$ and dhps genotyping $(\mathrm{N}=93), 6(6.5 \%)$ samples were carrying the quadrupule mutant $d h f r$ 51I, 59R, $108 \mathrm{~N}+d h p s$

Table 2 Prevalence of malaria parasites detected by realtime-PCR in pregnant women at six locations of Madagascar

\begin{tabular}{|c|c|c|c|c|c|c|c|c|c|c|c|c|c|c|}
\hline \multirow[b]{3}{*}{ Number of samples } & \multicolumn{6}{|c|}{ Coast } & \multicolumn{6}{|c|}{ Highlands } & \multicolumn{2}{|c|}{ Total $(\mathrm{N}=1242)$} \\
\hline & \multicolumn{2}{|c|}{$\begin{array}{l}\text { Mananjary } \\
(\mathrm{N}=195)\end{array}$} & \multicolumn{2}{|c|}{$\begin{array}{l}\text { Manakara } \\
(\mathrm{N}=249)\end{array}$} & \multicolumn{2}{|c|}{$\begin{array}{l}\text { Ifanadiana } \\
(\mathrm{N}=197)\end{array}$} & \multicolumn{2}{|c|}{$\begin{array}{l}\text { TDD } \\
(\mathrm{N}=203)\end{array}$} & \multicolumn{2}{|c|}{$\begin{array}{l}\text { Moramanga } \\
(\mathrm{N}=198)\end{array}$} & \multicolumn{2}{|c|}{$\begin{array}{l}\text { Ambositra } \\
(\mathrm{N}=200)\end{array}$} & \multirow[b]{2}{*}{$\mathbf{n}$} & \multirow[b]{2}{*}{$\%$} \\
\hline & $n$ & $\%$ & $n$ & $\%$ & $n$ & $\%$ & $\mathrm{n}$ & $\%$ & $\mathrm{n}$ & $\%$ & $\mathrm{n}$ & $\%$ & & \\
\hline P. falciparum & 25 & 12.8 & 51 & 20.5 & 19 & 9.6 & 21 & 10.3 & 27 & 13.6 & 14 & 7 & 157 & 12.6 \\
\hline P. malariae & 0 & - & 5 & 2 & 3 & 1.5 & 1 & 0.5 & 0 & - & 0 & - & 9 & 0.7 \\
\hline P. ovale & 0 & - & 0 & - & 1 & 0.5 & 0 & - & 0 & - & 0 & - & 1 & 0.1 \\
\hline P. vivax & 0 & - & 0 & - & 0 & - & 1 & 0.5 & 0 & - & 0 & - & 1 & 0.1 \\
\hline$P f+P m$ & 0 & - & 3 & 1.2 & 1 & 0.5 & 1 & 0.5 & 0 & - & 0 & - & 5 & 0.4 \\
\hline$P m+P_{0}$ & 0 & - & 0 & - & 1 & 0.5 & 0 & - & 0 & - & 0 & - & 1 & 0.1 \\
\hline
\end{tabular}

TDD, Tsiroanomandidy.

$\mathrm{N}$, Number of EDTA-blood samples collected.

$\mathrm{n}$, number of positive samples for Plasmodium species detection by realtime-PCR. 
Table 3 Effect of prevention used against malaria among pregnant women in Malagasy coast and highlands

\begin{tabular}{|c|c|c|c|c|c|c|c|c|c|}
\hline & & \multicolumn{4}{|c|}{ Coast } & \multicolumn{4}{|c|}{ Highlands } \\
\hline & & $\bar{N}$ & $P f+(\%)$ & OR [Cl 95\%] & $p^{*}$ & $\bar{N}$ & $P f+(\%)$ & OR [Cl 95\%] & $p^{*}$ \\
\hline \multirow[t]{2}{*}{ Gravidea } & 1 & 437 & $62(14.2)$ & $0.95[0.57-1.58]$ & 0.474 & 410 & $38(9.3)$ & $1.45[0.84-2.52]$ & 0.119 \\
\hline & $\geq 2$ & 170 & $23(13.5)$ & & & 178 & $23(12.9)$ & & \\
\hline \multirow[t]{2}{*}{ Bed net use } & no & 51 & $11(21.6)$ & 0.57 [0.28-1.16] & 0.09 & 309 & $32(10.4)$ & $0.93[0.55-1.59]$ & 0.452 \\
\hline & yes & 584 & 79 (13.5) & & & 288 & $28(9.7)$ & & \\
\hline \multirow[t]{2}{*}{ IPTp/SP } & no & 317 & $60(18.9)$ & $0.43[0.26-0.69]$ & $>0.001$ & 390 & $37(9.5)$ & $1.26[0.72-2.20]$ & 0.253 \\
\hline & yes & 310 & $28(9.0)$ & & & 189 & $22(11.6)$ & & \\
\hline
\end{tabular}

Pf+, Number of positive samples with Plasmodium falciparum by realtime-PCR.

$\mathrm{OR}$, odd ratio.

IPTp/SP, Intermittent Presumptive Treatment in pregnancy with sulphadoxine-pyrimethamine.

*Fisher's exact test.

437G. Very few samples carried mutations on pfmdr1 genes and the wild type allele of pfcrt K76 and dhps K540 were fixed in all location.

\section{Discussion}

This study on healthy pregnant women demonstrates that P. falciparum parasites can be found in resident populations of Madagascan lowlands and highlands. As classical microscopy has sensitivity limitations when parasite levels are low [15], the epidemiological analysis was based on PCR.

\section{Prevalence of infection and immunity}

Even in the highest study location, 1,200 m above sea level, $7 \%$ of healthy participants were P. falciparum positive. The permanent presence of $P$. falciparum in highland populations with very low levels of parasitaemia may maintain some level of partial immunity in the population indicated by the high seroprevalence in the area around $900 \mathrm{~m}$ above sea level (with $87.1 \%$ in Tsiroanomandidy and $84.8 \%$ in Moramanga). However, the weak clinical immunity together with a relevant parasite reservoir could initiate malaria epidemics like in Ambositra (1200 $\mathrm{m}$ above sea level) where the seroprevalence in pregnant women were around $30 \%$ and seems to be contracted in older category of age. Indeed, the malaria epidemics in the highlands between 1986 and 1988 were devastating with around 70,000 to 100,000 deaths every year [2]. Therefore, a significant frequency of submicroscopic malaria parasite carriage has to be considered for the planning of control

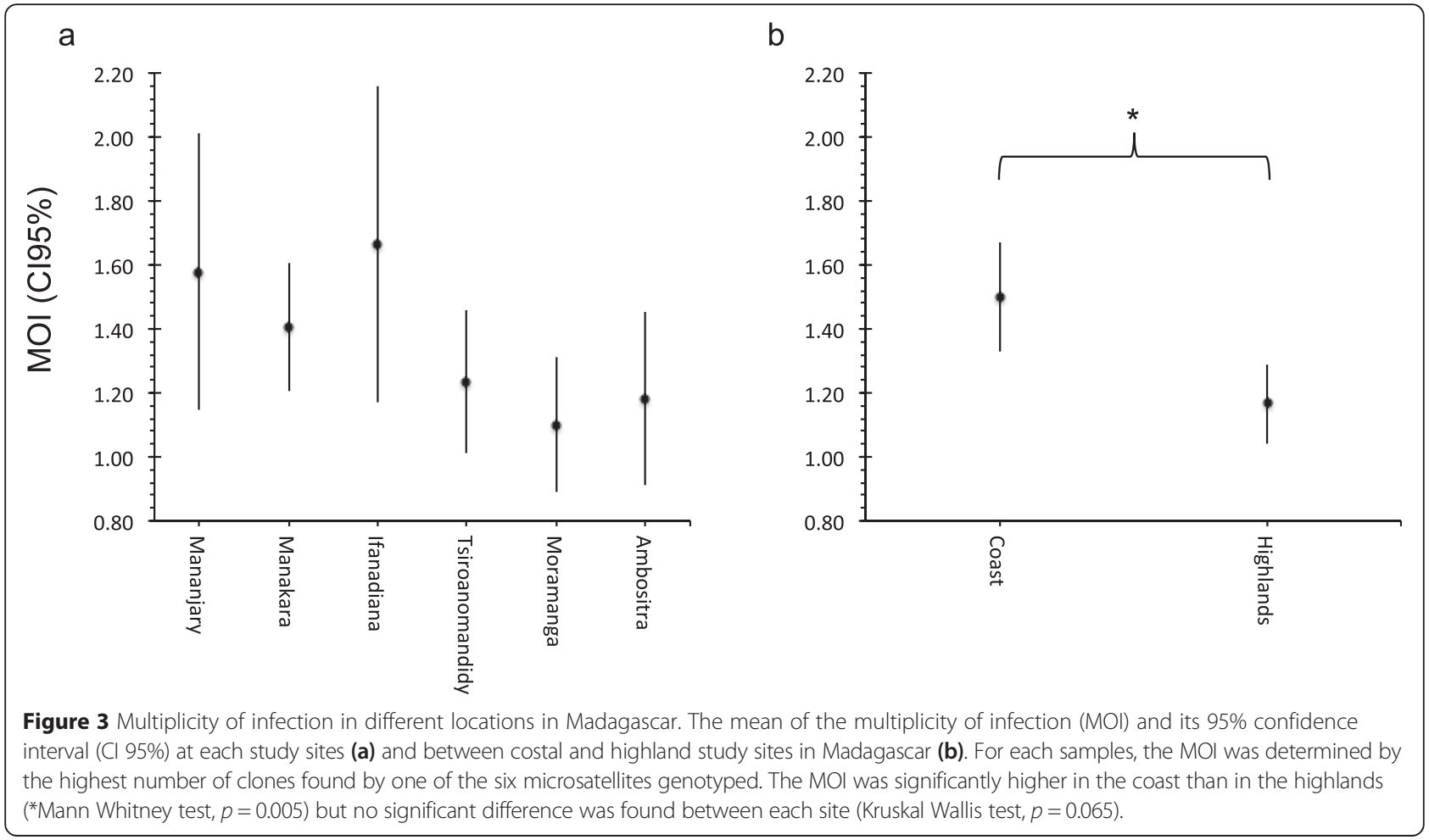


Table 4 Polyclonality of malaria infection in six locations in Madagascar

\begin{tabular}{|c|c|c|c|c|c|c|c|c|c|c|c|c|}
\hline \multirow{3}{*}{ Number of clones } & \multicolumn{6}{|c|}{ Coast } & \multicolumn{6}{|c|}{ Highlands } \\
\hline & \multicolumn{2}{|c|}{$\begin{array}{l}\text { Mananjary } \\
(\mathrm{N}=19)\end{array}$} & \multicolumn{2}{|c|}{$\begin{array}{l}\text { Manakara } \\
(\mathrm{N}=37)\end{array}$} & \multicolumn{2}{|c|}{$\begin{array}{l}\text { Ifanadiana } \\
(\mathrm{N}=12)\end{array}$} & \multicolumn{2}{|c|}{$\begin{array}{l}\text { TDD } \\
(\mathrm{N}=17) \\
\end{array}$} & \multicolumn{2}{|c|}{$\begin{array}{l}\text { Moramanga } \\
(\mathrm{N}=20)\end{array}$} & \multicolumn{2}{|c|}{$\begin{array}{l}\text { Ambositra } \\
(\mathrm{N}=11)\end{array}$} \\
\hline & $\mathrm{n}$ & $\%$ & $\mathrm{n}$ & $\%$ & $\mathrm{n}$ & $\%$ & $n$ & $\%$ & $\mathrm{n}$ & $\%$ & $n$ & $\%$ \\
\hline 1 & 12 & 63.2 & 24 & 64.9 & 6 & 50 & 13 & 76.5 & 19 & 95 & 9 & 81.8 \\
\hline 2 & 4 & 21.1 & 11 & 29.7 & 4 & 33.3 & 4 & 23.5 & 0 & - & 2 & 18.2 \\
\hline 3 & 2 & 10.5 & 2 & 5.4 & 2 & 16.7 & 0 & - & 1 & 5 & 0 & - \\
\hline 4 & 1 & 5.3 & 0 & - & 0 & - & 0 & - & 0 & - & 0 & - \\
\hline MOI [Cl 95\%] & \multicolumn{2}{|c|}{$1.6[1.1-2.0]$} & \multicolumn{2}{|c|}{$1.4[1.2-1.6]$} & \multicolumn{2}{|c|}{$1.7[1.2-2.2]$} & \multicolumn{2}{|c|}{$1.2[1.0-1.5]$} & \multicolumn{2}{|c|}{$1.1[0.9-1.3]$} & \multicolumn{2}{|c|}{$1.2[0.9-1.5]$} \\
\hline
\end{tabular}

TDD, Tsiroanomandidy.

$\mathrm{MOI}$, multiplicity of infection.

$\mathrm{N}$, Number of Plasmodium falicparum samples able to be genotyped for microsatellite loci.

measures [16]. Indeed, efficient transmission to mosquitoes has been demonstrated also at submicroscopic gametocyte densities $[1,17]$.

\section{Control of malaria in the highlands}

In this study, the use of bed nets or chemoprophylaxis was associated with a reduction of infections in participants from the coast. Currently, malaria control in the Malagasy highlands is mainly based on indoor insecticide spraying [7]. It cannot be excluded that parasites detected in highland locations were acquired at the coast and then imported as it occurs in the capital Antananarivo [18]. Nevertheless, the data indicate a certain level of transmission in the central highlands because only one of 601 women from the highlands travelled to a coastal location within the last half of year. Transmission in the highlands is supported by entomological surveys that have shown the occurrence of malaria vectors, such as Anopheles gambiae, at altitudes above 1,200 $\mathrm{m}$ [19].

\section{Mutations providing resistance against chloroquine and} sulphadoxine-pyrimethamine

An unusual haplotype carrying the single nucleotide polymorphism (SNP) I164L on the dhfr gene involved in

Table 5 Effect of prevention used against malaria among pregnant women on the MOl in Malagasy coast and highlands

\begin{tabular}{|c|c|c|c|c|c|c|c|}
\hline & \multicolumn{3}{|c|}{ Coast } & \multicolumn{3}{|c|}{ Highlands } \\
\hline & & $\mathrm{N}$ & $\mathrm{MOI}$ & $p^{*}$ & $\mathrm{~N}$ & $\mathrm{MOI}$ & $p^{*}$ \\
\hline \multirow[t]{2}{*}{ Age } & $<20$ & 20 & 1.7 & 0.142 & 11 & 1.27 & 0.418 \\
\hline & $\geq 20$ & 48 & 1.42 & & 34 & 1.15 & \\
\hline \multirow[t]{2}{*}{ Bed net use } & no & 9 & 2 & 0.028 & 28 & 1.14 & 0.605 \\
\hline & yes & 58 & 1.43 & & 19 & 1.21 & \\
\hline \multirow[t]{2}{*}{ IPTp/SP } & no & 48 & 1.52 & 0.71 & 29 & 1.21 & 0.229 \\
\hline & yes & 18 & 1.44 & & 18 & 1.01 & \\
\hline
\end{tabular}

MOI, multiplicity of infection.

IPTp/SP, Intermittent Presumptive Treatment in pregnancy with sulphadoxinepyrimethamine.

*Mann Whitney test. pyrimethamine resistance was previously found only in Madagascar [20]. This SNP was detected in three samples from pregnant woman out of 70 genotyped but never in association with the triple mutation $d h f r$ 51I, 59R, 108N that is associated with a high resistance of $P$. falciparum against antifolate drugs [21]. On the other hand, four samples carrying the quadruple mutant dhps $437 \mathrm{G}+$ dhfr 51I, 59R, 108N in Manakara (11.8\%) and two samples in Tsiroanomandidy (15.4\%) were found. Accumulation of mutations in these two genes is associated with in vivo SP resistance [22]. Similar findings were previously reported from samples collected in Madagascar from 2006 to 2008 [20]. Even if these findings are not alarming, a constant monitoring of SP resistance is advisable because SP is the drug of choice for malaria prevention in pregnancy.

Prevalence of the principal resistance marker for CQ pfcrt 76T was low in Madagascar compared to continental Africa [23]. However, in vivo resistance to CQ in Madagascar that is not associated with the mutation pfcrt 76T but with the mutation pfmdr1 86Y was found and perhaps yet unknown mechanism were involved $[24,25]$. In our study we found that the prevalence of pfmdr1 86Y was low compared to previous data [20,23-25] maybe because of the change of the first line policy from CQ to artemisinin combination therapy (ACT). Nevertheless, a recent publication [14] has shown that the wild-type pfmdr1 N86 SNP is associated with recrudescence of malaria infection after artemether-lumefantrine treatment in Benin. Studies on emerging ACT resistance can provide more information for the guideline of malaria treatment in Madagascar.

\section{Multiplicity of infection}

Lower numbers of different parasite strains were found in infected women from the highlands compared to the coast. This was expected, as multiplicity is a function of transmission likelihood. The average of two to four $P$. falciparum strains in the two coastal areas are in accordance with what was described in areas of moderate to 


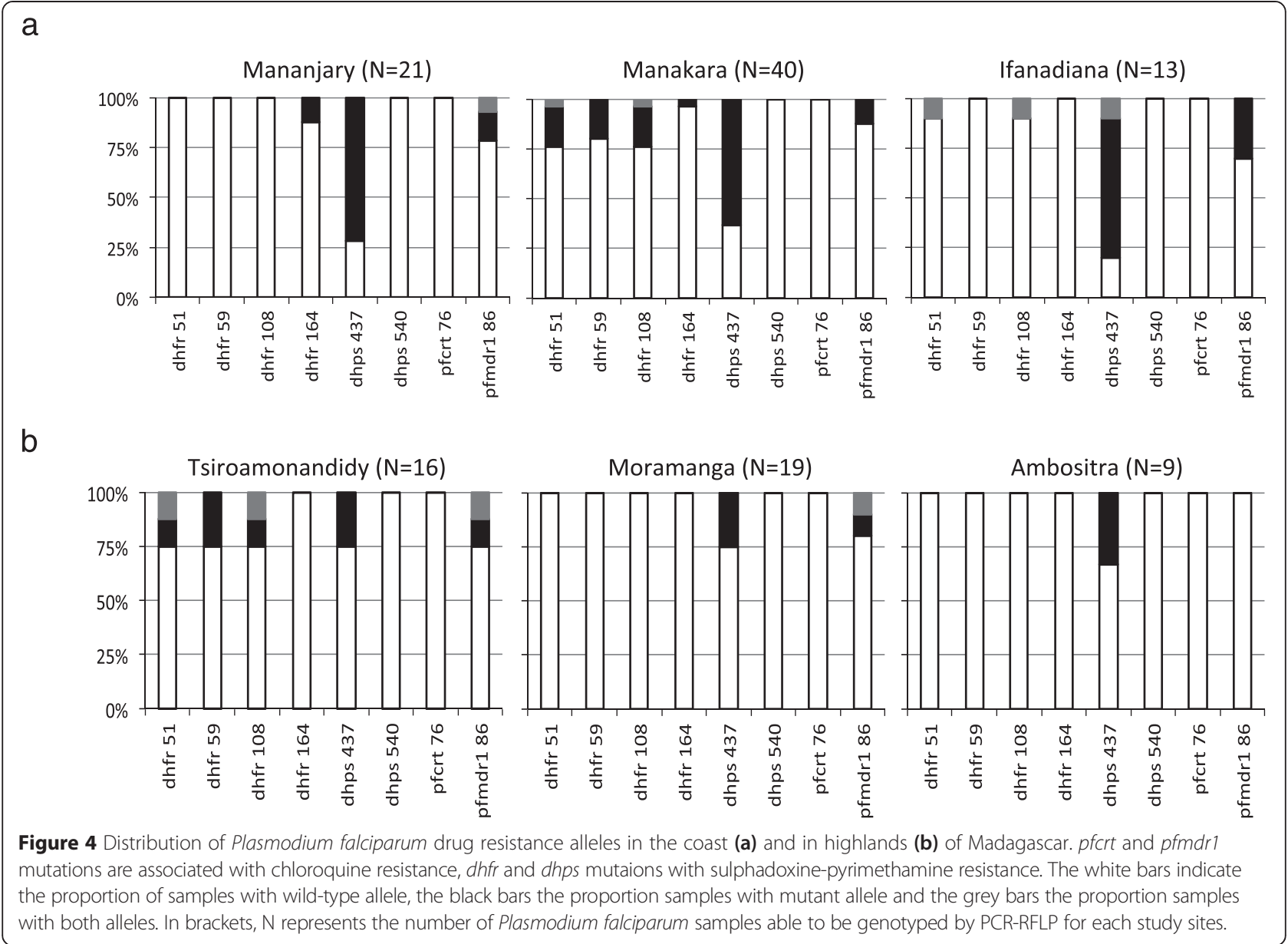

high endemicity [26]. Low parasite diversity combined with low endemicity are factors associated with emergence of malaria drug resistance like in South America or SouthEast Asia [27]. The findings presented here are based on a relative homogeneous subgroup of the population at risk. Similar studies including children and also other adults are needed to get more information on asymptomatic malaria parasite carriers at different altitudes.

\section{Effect of preventive measures on parasite carriage}

In this study, the use of chemoprophylaxis (IPTp/SP) and vector control (bed net) was assessed among pregnant women from costal and highland locations of Madagascar. The use of those preventive measures against malaria was associated with the reduction of around 50\% falciparum parasite carriage and also with the reduction of the number of clones of parasites in one infection, especially in the coastal area where the population are targeted by the mass distribution of long-lasting insecticidal nets and IPTp.

The findings of this study are in accordance with the conclusion of the nationwide evaluation of malaria infection and coverage of malaria control interventions in
Madagascar, which took place in 2012-2013 [28]. Malaria control interventions should consider the whole population from the endemic area like the coast but also from the highlands.

\section{Conclusion}

This study demonstrated that asymptomatic malaria parasite carriers occur in Madagascar up to altitudes of $1,200 \mathrm{~m}$ with seroprevalences under $50 \%$. The constellation of an existing reservoir and low immunity in the population is prone for malaria epidemics. The prevalence of drug resistance markers is still not alarming compared to some areas in the African mainland but monitoring might be valuable in Madagascar where malarial parasites seem to have different drug resistance mechanism than in other areas. As the Malagasy National Malaria Control Programme is moving toward the elimination of malaria in the highlands, monitoring of the existence of parasites in asymptomatic individuals becomes more important. More sensitive technology like PCR based diagnostic for the detection of submicroscopic parasitemia provides useful information for malaria control. 


\section{Additional file}

\section{Additional file 1: Primers and probes used to determine Plasmodium species by realtime-PCR and to genotype six neutral $P$. falciparum microsatellites.}

\section{Competing interests}

The authors declare that they have no competing interests.

\section{Authors' contributions}

OMA carried out the molecular genetic studies and drafted the manuscript. RR participated in the design and the coordination of the study. MG and NR conducted the study and collected the data. AH performed the statistical analysis. SP carried out the immunofluorescence test. JM designed and supervised the study. NGS conceived of the study and helped to draft the manuscript. All authors read and approved the final manuscript.

\section{Acknowledgements}

We thank all participants who donated blood for their kind cooperation. We thank the medical doctors and nurses at the health care centers in Madagascar for their help, support and helpful discussion on the project. We acknowledge Christian Keller and Ute Melhoop for providing the malaria species detection method by real-time PCR, Alexandra Veit for her technical assistance in conducting the immunofluorescence test, Sascha Kröncke for his help in the molecular genetic assays and Nicolas Addofoh for his support in the data analysis. We are grateful to Ralf Krumkamp for his critical reading of the manuscript.

\section{Author details}

${ }^{1}$ Bernhard-Nocht Institute for Tropical Medicine, Hamburg, Germany.

${ }^{2}$ University of Antananarivo, Antananarivo, Madagascar.

${ }^{3}$ Justus-Liebig-University, Giessen, Germany.

Received: 5 December 2014 Accepted: 22 April 2015

Published online: 03 May 2015

\section{References}

1. Ouedraogo AL, Bousema T, Schneider P, de Vlas SJ, Ilboudo-Sanogo E, Cuzin-Ouattara N, et al. Substantial contribution of submicroscopical Plasmodium falciparum gametocyte carriage to the infectious reservoir in an area of seasonal transmission. PLoS One. 2009;4:e8410.

2. Mouchet J, Laventure S, Blanchy S, Fioramonti R, Rakotonjanabelo A, Rabarison $\mathrm{P}$, et al. [The reconquest of the Madagascar highlands by malaria](in French). Bull Soc Pathol Exot. 1997;90:162-8.

3. Razanamparany MS, Randriamiharisoa FA, Razanamparany NJ, Ramialimanana V. [The malaria epidemic in Antananarivo from 1983 to 1994 as seen through the Pediatric Service A in the Befelatanana General Hospital](in French). Sante. 1995;5:382-5.

4. Mouchet J, Blanchy S. [Particularities and stratification of malaria in Madagascar](in French). Sante. 1995;5:386-8.

5. Fontenille D, Rakotoarivony I. Reappearance of Anopheles funestus as a malaria vector in the Antananarivo region, Madagascar. Trans R Soc Trop Med Hyg. 1988:82:644-5.

6. Lepers JP, Deloron P, Fontenille D, Coulanges P. Reappearance of falciparum malaria in central highland plateaux of Madagascar. Lancet. 1988;1:586.

7. Ministère de la Santé Publique de Madagascar: Plan strategique de lutte contre le paludisme Madagascar 2013-2017, Antananarivo, Madagascar. [www.rollbackmalaria.org/files/files/countries/madagascar2013-2017.pdf]

8. Andriantsoanirina V, Ménard D, Tuseo L, Durand R. History and current status of Plasmodium falciparum antimalarial drug resistance in Madagascar. Scand J Infect Dis. 2010;42:22-32.

9. Randrianarivelojosia M, Raveloson A, Randriamanantena A, Juliano JJ, Andrianjafy T, Raharimalala LA, et al. Lessons learnt from the six decades of chloroquine use (1945-2005) to control malaria in Madagascar. Trans R Soc Trop Med Hyg. 2009;103:3-10.

10. Wickremasinghe R, Fernando SD, Thillekaratne J, Wijeyaratne PM, Wickremasinghe AR. Importance of active case detection in a malaria elimination programme. Malar J. 2014;13:186.

11. Schwarz NG, Girmann M, Randriamampionona N, Bialonski A, Maus D, Krefis AC, et al. Seroprevalence of antibodies against Chikungunya, dengue, and Rift Valley fever viruses after febrile illness outbreak, Madagascar Emerg Infect Dis. 2012;18:1780-6.

12. Wilson M, Sulzer AJ, Runcik K. Malaria-antibody patterns as determined by the IFA test in U.S. servicemen after chemotherapy. Am J Trop Med Hyg. 1970;19:401-4

13. Anderson TJ, Su XZ, Bockarie M, Lagog M, Day KP. Twelve microsatellite markers for characterization of Plasmodium falciparum from finger-prick blood samples. Parasitology. 1999;119:113-25.

14. Dahlström S, Aubouy A, Maïga-Ascofaré O, Faucher JF, Wakpo A, Ezinmègnon $\mathrm{S}$, et al. Plasmodium falciparum polymorphisms associated with ex vivo drug susceptibility and clinical effectiveness of artemisinin-based combination therapies in Benin. Antimicrob Agents Chemother. 2014;58:1-10.

15. Harris I, Sharrock WW, Bain LM, Gray KA, Bobogare A, Boaz L, et al. A large proportion of asymptomatic Plasmodium infections with low and sub-microscopic parasite densities in the low transmission setting of Temotu Province, Solomon Islands: challenges for malaria diagnostics in an elimination setting. Malar J. 2010;9:254.

16. Okell LC, Bousema T, Griffin JT, Ouedraogo AL, Ghani AC, Drakeley CJ. Factors determining the occurrence of submicroscopic malaria infections and their relevance for control. Nat Comm. 2012;3:1237.

17. Schneider P, Bousema JT, Gouagna LC, Otieno S, van de Vegte-Bolmer M, Omar SA, et al. Submicroscopic Plasmodium falciparum gametocyte densities frequently result in mosquito infection. Am J Trop Med Hyg. 2007;76:470-4

18. Domarle $\mathrm{O}$, Razakandrainibe R, Rakotomalala E, Jolivet L, Randremanana RV, Rakotomanana F, et al. Seroprevalence of malaria in inhabitants of the urban zone of Antananarivo, Madagascar. Malar J. 2006;5:106.

19. Tantely ML, Rakotoniaina JC, Tata E, Andrianaivolambo L, Fontenille D, Elissa N. Modification of Anopheles gambiae distribution at high altitudes in Madagascar. J Vector Ecol. 2012;37:402-6.

20. Andriantsoanirina V, Ratsimbasoa A, Bouchier C, Jahevitra M, Rabearimanana S, Radrianjafy $\mathrm{R}$, et al. Plasmodium falciparum drug resistance in Madagascar: facing the spread of unusual pfdhfr and pfmdr-1 haplotypes and the decrease of dihydroartemisinin susceptibility. Antimicrob Agents Chemother. 2009;53:4588-97.

21. Hankins EG, Warhurst DC, Sibley CH. Novel alleles of the Plasmodium falciparum dhfr highly resistant to pyrimethamine and chlorcycloguanil, but not WR99210. Mol Biochem Parasitol. 2001;117:91-102.

22. Nzila AM, Mberu EK, Sulo J, Dayo H, Winstanley PA, Sibley CH, et al. Towards an understanding of the mechanism of pyrimethamine-sulfadoxine resistance in Plasmodium falciparum: genotyping of dihydrofolate reductase and dihydropteroate synthase of Kenyan parasites. Antimicrob Agents Chemother. 2000;44:991-6.

23. Maïga-Ascofaré $\mathrm{O}$, Le Bras J, Mazmouz R, Renard E, Falcão S, Broussier E, et al. Adaptive differentiation of Plasmodium falciparum populations inferred from single-nucleotide polymorphisms (SNPs) conferring drug resistance and from neutral SNPs. J Infect Dis. 2010;202:1095-103.

24. Rason MA, Andrianantenaina HB, Ariey F, Raveloson A, Domarle O, Randrianarivelojosia M. Prevalent pfmdr1 n86y mutant Plasmodium falciparum in Madagascar despite absence of pfcrt mutant strains. Am J Trop Med Hyg. 2007;76:1079-83.

25. Andriantsoanirina V, Ratsimbasoa A, Bouchier C, Tichit M, Jahevitra M, Rabearimanana S, et al. Chloroquine clinical failures in Plasmodium falciparum malaria are associated with mutant Pfmdr-1, not Pfcrt in Madagascar. PLoS One. 2010;5:e13281.

26. Schoepflin S, Valsangiacomo F, Lin E, Kiniboro B, Mueller I, Felger I. Comparison of Plasmodium falciparum allelic frequency distribution in different endemic settings by high-resolution genotyping. Malar J. 2009;8:250.

27. White NJ, Pongtavornpinyo $W$. The de novo selection of drug-resistant malaria parasites. Proc Biol Sci. 2003;270:545-54.

28. Kesteman $T$, Randrianarivelojosia M, Mattern C, Raboanary E, Pourette D, Girond F, et al. Nationwide evaluation of malaria infections, morbidity, mortality, and coverage of malaria control interventions in Madagascar. Malar J. 2014;13:465. 